\title{
The predicament of history
}

\author{
Bill Schwarz
}

The moment in 1968 when C. L. R. James explicitly named a tradition of West Indian intellectuals symbolised an ending rather than a beginning. Essentially, the West Indian intellectual, so named, was a colonial phenomenon. As Catherine Hall demonstrates in the opening chapter, the term 'West Indian' always represented a complex of competing ideas, a resource for both colonial and anticolonial politics. Its meanings in any particular historical situation derived from the overall balance of forces between colony and metropolis. By the time independence was in sight 'West Indian' had principally come to signify the aspiration of the anglophone peoples of the Caribbean for a future free from colonial rule, in which the deepest instincts of the formerlycolonised would find unimpeded expression. That this transformation in meaning had occurred was due to the determination of Caribbean intellectuals, broadly conceived, to devise an identity which was theirs, and which belonged to those whom they represented. Once independence had been achieved, however, and once new political circumstances obtained (the impact of the Cuban Revolution; the coming of Black Power), inherited traditions found themselves facing radical interrogation on every front. Historical time itself seemed to accelerate. Thought previously championed as West Indian was recast in new forms, as Caribbean, or Black. 'West Indian' spoke too easily of earlier - colonial - times.

In the urban landscapes of contemporary Britain there are few visible traces of the social history of West Indian intellectual activity, despite the magnitude of the great migration from the Caribbean. No cafés or book or record shops or dance halls carry commemorative plaques, or retain a place in the larger collective memory. ${ }^{1}$ Even educated opinion can still profess a certain puzzlement that there could be such a thing as an intellectual tradition deriving from the experience of the Caribbean, testament to the continuing power of colonial mentalities. 
If this tradition is recalled at all it is so as something local, only of concern to the West Indians themselves and disconnected from all that was significant in British life.

Of those whom we discuss, only Naipaul now lives in the old metropole, and he has chosen to do so as literary grandee, the Tartuffe of West Indian literary endeavour: elevated, isolated, eccentric, only ever appearing in order to send a pot-shot or two towards those whom he perceives to be instigators of an ever-gathering, demotic barbarism. Some of Naipaul's generation found themselves remaining in the UK; others re-crossed the seas once more to North America; and a minority discovered ways in which they could reinhabit their own homelands in the Caribbean. For younger generations of Caribbean thinkers and artists the allure of Britain and its capital has long since faded. Long before the exodus to Britain in the middle of the last century Caribbean peoples had been accustomed to migration, either within the region itself or further afield. Britain was only ever 'one stop in a sequence': distinct, of course, in very many ways, but nonetheless only part of a larger, more varied collective memory. ${ }^{2}$

Why, then, should we return to this colonial moment? Why should we be concerned with a tradition of social thought which, it might seem, even in its own nations came to be superseded the very moment it claimed its existence? And why should we be so exercised about the British dimensions of this story when all the evidence suggests that the British themselves regard it as something which barely pertains to them at all?

If nothing else, we hope to have shown how wrong it is to assume that the West Indian presence was somehow disconnected from the British and their civilisation. If this argument has been won, as perhaps it has within the historiography, there might then be any number of reasons to encourage us to return to this past. But the most pressing may be the one which historians are usually most reluctant to confront: the idea that in recovering these traditions of West Indian thought we ourselves, in Britain, might be able to think more creatively about our own historical situation. Or in other words, the overriding reason may be an intellectual one, drawing into question our own analytical procedures.

In the middle decades of the twentieth century mass emigration from the Caribbean coincided with the final phase of decolonisation. This represented a particular conjunction of events, with significant consequences, for to an uncommon degree much of the intellectual work of Caribbean decolonisation was conducted in the metropolis. The metropolitan locations of, say, Caribbean Voices, or of the Caribbean Artists Movement, let alone of the preoccupations of particular individuals, are themselves historical facts of importance. Exile constituted the 


\section{BILL SCHWARZ}

mise-en-scène for Caribbean decolonisation. This has been recognised well enough within the Caribbean, if not in Britain. The fact that substantial elements of Caribbean thought were produced in the metropolis is neither contingent nor merely the occasion for fleeting curiosity. Location mattered, shaping the intellectual life which emerged. As we have argued, the West Indians were colonial Britons who experienced the civilisation of the British, in Britain, from a very particular vantage. It is the resultant perspectives on British civilisation that we've attempted to retrieve in the preceding chapters. Here were generations of West Indians encountering the civilisation of the empire in its very heartlands, who determined to work through for themselves an idea of life after colonialism. If for the domestic British decolonisation was something which occurred 'elsewhere' - overseas and out of sight - then the Caribbean experience may provide a partial exception: it happened, had those in the metropole only been able to see, before their very eyes.

In recovering these traditions of intellectual thought we might more easily be able to imagine what, for us in Britain, becoming postcolonial entails. To say this is to recognise that the work of becoming postcolonial has yet to be completed. In turn, to argue in these terms is to argue for the intellectual power of history. It suggests that unseen in the past are experiences which can valuably be brought to bear on the present. That past, we suggest, can be revealed in such a way that it can speak to the situation of our present.

The chapters in this volume provide many clues which indicate how, from our chosen perspective, we might isolate the specifics of the intellectual contribution of West Indians in Britain. To conclude, in summary form, I'll indicate just three overlapping and interconnected areas of thought: race and ethnicity; the project of decolonisation; and the historical imagination itself.

On race and ethnicity I'll say only a little. There is no doubt that of those non-white West Indians we discuss, born before the cataclysm of the 1930s, the majority strove hard in their personal lives to rise above race. In this, the political ultras, James and Padmore, were little different from self-styled moderates, such as Moody. (McKay, as so often, represents the exception; Marson is perhaps the most intriguing.) To transcend one's colonial status and become a fully modern subject required, they believed, relegating the subjective travails of racial subordination to the status of the interpersonal, which they couldn't regard as properly political. James's imaginings of race were certainly complex, leading him on occasion to positions which from a contemporary perspective look very odd. But even so, the various silences enveloping the lived experiences of racial subjugation did not prevent the emergence of analyses of Britain in which race was accorded a cen- 
tring, systemic conceptual role. Padmore's theorisation of the empire as a system of racialised exploitation was of huge importance in this regard; but so too, in a different manner, was Moody's growing conviction of the power of racism deep in the heart of the metropolis. Positions such as these represented a provocation to the official upholders of nation and empire, to a degree which is difficult for us who live in different historical times to comprehend. But out of the confrontations which followed, there slowly evolved the possibilities for a politics of race to become speakable in the public domain, and for new thought to flourish.

The force of much of this thinking was negative, highlighting the hidden or not-so-hidden racial codes of imperial imaginings. Implicitly, it interrogated the imperatives of whiteness. But it simultaneously created the conditions for reconceptualising black, and the impetus for elaborating a philosophy of human life able fully to incorporate the formerly-enslaved and colonised. There were many strands to this intellectual movement, which shouldn't be conflated. For our purposes, though, we might point to the personal and intellectual connections established between the West Indian migrants in Britain and, to put this loosely, non-British cultures of thought. The controversial estimations of Jean Rhys's commitments to a heterodox négritude are significant in this respect. So too, as Mary Chamberlain establishes, was George Lamming's entry in the middle 1950s into the Parisian intellectual milieu which brought together Sartrean phenomenology and négritude - from which so much contemporary thinking on 'the fact of blackness' has subsequently derived. Insofar as French philosophy touched the intellectual culture of the British in the 1950s and early 1960s, the preoccupation with the question of black subjectivity barely registered at all, despite its centrality. Its presence in the West Indian diaspora half a century ago anticipated much contemporary conceptual inquiry.

So too, in a later transformation, West Indians in Britain in the 1960s were in the forefront of introducing into the metropolis the various political philosophies deriving from Civil Rights and Black Power. ${ }^{3}$

Maybe this is only to state what readers might expect: that out of the lived experience of Britain's non-white populations emerged the means to conceptualise and to counter the logics of racial thought. But if this seems self-evident, the detailed, situated, historical story remains far from clear - as do the resulting ambiguities. For the reasons we describe, the West Indian dimension has been an influential component of this larger story. So much so that its very obviousness can inhibit, rather than encourage, critical reflection.

Second, raising some of the same issues, is the problem of decolonisation. Decolonisation can be thought from a narrow purview, in 
which the transfer of political sovereignty marks the final end of colonial domination. This literal rendition is obviously necessary, but it remains partial. The extraordinarily creative assertion of West Indian thought in the middle of the twentieth century, which effectively encompassed - amongst other things - the making of the West Indian novel, presaged a more expansive conception of decolonisation, in which the end of colonial rule would signal not merely a transfer of political power, but the renovation of the entire colonial civilisation, from top to bottom. In the decade or so from the middle 1950s to the middle 1960s this dedication to the decolonisation of the culture of the Caribbean moved to the centre of what it was to declare oneself a West Indian. In the writings of the time of C. L. R. James, George Lamming or Claudia Jones, for example, one can plot the crystallisation of this mode of thought. Rather than conceiving of decolonisation as a passive affair, orchestrated by the political leaders from above, the more radical of the West Indian intellectuals came to imagine a more fully popular transformation, in which the people themselves would take active charge of commanding their own historical destinies.

To think of decolonisation in this expansive manner opened an entire new domain of thought. One of the forces driving the emergence of the West Indian novel had been the need felt by a new generation of writers, in the wake of the labour riots of the 1930s, to devise a form in which the indigenous popular voices of the Caribbean could be articulated. That this was only ever partially achieved can be seen from the debates generated within the Caribbean Artists Movement in the later 1960s, where the question of creating appropriate popular forms was incessantly addressed, and where it became the cause, it seems, of incessant disputation. The issue of the popular brought the cultural activists of CAM hard up against the question of British civilisation: how, in politics, in the aesthetic imagination, in the everyday organisation of civic life, and perhaps most of all in language itself, were the legacies of the colonial epoch to be overcome? Moreover: if popular life in the Caribbean represented the stratum of the cultural order least touched by European norms - blacker, say, or more non-white; where Africa or Asia were more proximate; more heterogeneous and hybrid, more Caribbean - then where did this leave those who had been most deeply formed, in intellect and bearing, in the schools and colleges of the British system? How could they, their learning notwithstanding, represent the universal aspirations of the Caribbean peoples?

There were as many resolutions to these dilemmas as there were people asking the questions. In the biography and intellectual career of Kamau Brathwaite, for example, we can see one particularly dramatic working through of these issues, a process punctuated by many refash- 
ionings and inventions of the self, but where overall the movement from a Britain to an Africa of the mind prevails. For all his singularities, Brathwaite is nonetheless representative. Other Caribbean intellectuals of his generation have not made his choices, or not made them with his commitments. But each has felt compelled to discover a strategy for divesting themselves of something of what the mother country had bestowed upon them.

To be confronted by the question of British civilisation in this way, not only as a matter of the formal exterior culture but as a matter of the self, was to understand the intricacy of the interrelations between a civilisation and political power. Or more radically, it marked the recognition that civilisation, the symbolic ordering of human life, is power. Today, with the insights of Gramsci and Foucault part of the common currency of at least some domains of the academic intellectual culture, such notions trip easily from the tongue. A generation ago this was not so. In the British case - yet more if we were to think of the dominating position of English culture - there barely existed a conceptual vocabulary in which such a critique could be expressed. Imagine suggesting that the ineffable refinement of the English, or the cultivated sensibility of their greatest men of letters, encoded a system of active, continuing authority. How preposterous! How vulgar! Yet we can discern a group of texts - most notably George Lamming's The Pleasures of Exile, C. L. R. James's Beyond a Boundary, and Claudia Jones's West Indian Gazette - which, in their different idioms, attempted to create a language in which just such insights could be deployed.

This, however, is where location intervenes most sharply. Those writers from the West Indies who had crossed the seas were not only confronting a colonial Britishness, organised island by island, but the Britishness of the mother country itself. From their situation, the interconnections between colony and metropolis were vividly present. In order to achieve decolonisation in their home nations, they had to engage the source of colonial authority, in the culture of the metropolis. But that is also where they were, working and living as migrants. The social and cultural hierarchies in metropolis and colony were not the same: but they demonstrably derived from the same principles which articulated what a civilisation was, and how it should operate. The West Indian migrant could experience herself or himself to be colonised as much in the metropolis as in their island colony: in fact, after independence, the experience of colonisation could be felt more keenly in the metropolis. From this could derive the following paradoxical idea: that in the realm of culture, the metropolis too needed to be decolonised.

We can see something of this happening. At the start of 1962 George Lamming contributed an article to the West Indian Gazette. He told of 


\section{BILL SCHWARZ}

a visit to a working-class neighbour in Chiswick early on in his time in England, and contrasted that experience to dinner at high table at a Cambridge University college. Dinner at high table brought home to him the intractable complexity of the unspoken rituals of upper-class England. His hosts at Cambridge represented, he believed, a culture which was entirely centred, conscious only of the fact that those whose lives fell outside its boundaries were somehow aberrant, lacking in refinement, reason and cultivation. Lamming's friend in Chiswick inhabited a different mental universe. He told Lamming that when he listened to the wireless he only tuned into the Light Programme, 'knowing' that the other programmes - devoted to Shakespeare (as he put it) - were not for him. 'I realised', wrote Lamming, 'that almost twothirds of the population of this country were in a colonial relation to the culture and traditions which were called England. And it was at this point that my own process of decolonisation began. ${ }^{4}$

This brief reflection raises many points of great interest. It suggests, amongst other things, that the work of decolonisation in its expansive register requires popular self-activity, not only on the part of the colonised but on the part too of the native citizens of the metropolis. Implicitly, Lamming was insisting that there exists an inextricable connection between the postcolonial and the creation of new vernacular forms: that to become fully postcolonial depends on the maximal expansion of popular life.

I don't mean to privilege the West Indians at the cost of ignoring other intellectual innovators of the period. It was not only West Indians of the diaspora who were opening up the issue of race, or expanding the notion of decolonisation, or theorising the centrality of the popular in new ways. All I would propose is that the historical situation of the migrants from the Caribbean gave their rendering of these issues a peculiar urgency, or immediacy, which more easily enabled them to connect what otherwise appeared to exist in isolation.

To listen to Lamming talking of the contrasts between working-class Chiswick and the high tables of Cambridge is to be reminded of a different, if contemporaneous, intellectual formation. The determination to elaborate an anthropological and democratic conception of culture of the British undertaken by Raymond Williams, Edward Thompson and Richard Hoggart in the 1950s and early 1960s reproduced a critical stance paralleling that which that can be found in the work of the West Indians. Williams and Hoggart (Thompson less so) made their journeys from the provinces to the centred redoubts of English civilisation. They too found themselves compelled to compile their ethnographic accounts and political audits of the 'traditions which were called England', fully aware that in so doing they were exploring the mechanisms by which a civilisation 
simultaneously organised structures of inclusion and exclusion. They too imagined a new popular will, capable of dismantling inherited social hierarchies. But their theoretical tone remained distinct. Their readiness to fall back on a radical nationalism, to ignore or downplay issues of race and racism, and their failures to think through the constitutive interaction between metropole and colony have for long been a source of controversy. ${ }^{5}$ One cannot easily imagine them, or those who shared their vision, thinking through these issues, in these years, in terms of the decolonisation of the British.

Close to Williams, Thompson and Hoggart, though, was one who did: Stuart Hall, who moved easily between the distinct perspectives of these two intellectual formations. By any reckoning, Hall was in his making a West Indian intellectual. The journey from Kingston, Jamaica, to Oxford University in 1951 conformed exactly to that generic crossing of seas which we have described throughout these pages. Yet the degree to which this formative experience is excised from accounts of his intellectual life, or given merely a gestural place, can be startling. Conventional wisdom in Britain presents him as a figure who entered intellectual life in the middle 1950s, as one of the inspirations for the emergent New Left, and who thence moved seamlessly into becoming the effective progenitor of what has subsequently become known as British cultural studies. This is a reading which entirely ignores his earliest publications and his active involvement in the network of West Indian cultural institutions in London in the 1950s; it ignores his continuing involvement with Caribbean organisations in Britain through the 1960s; and it ignores too the complicated but significant role he has played in Caribbean intellectual life in the Caribbean, in his homenation of Jamaica and beyond. What I've indicated here as constituting the defining preoccupations of mid-twentieth-century West Indian intellectual life in Britain - the developing critique of racial systems; the concern with the displacement of political authority in symbolic or cultural forms; the implacable commitments to maximise and cherish the power of innovative vernacular forms; the expansive conception of what comprised the civilisation of the British; and the consequent understanding that future emancipation required cultural work on the broadest front - all these are not merely close to the heart of Hall: he gave them voice in Britain, addressing a British as much a West Indian audience. In these terms one can see how Hall has worked to translate elements of West Indian traditions of thought into a broader philosophy or theory of culture, which has served as the basis for a series of conjunctural analyses of the civilisation of the British. From early on, he worked as a kind of relay by which the debates and discussions of the West Indians could acquire a wider influence in the national cultures of 


\section{BILL SCHWARZ}

Britain, and by which they could reach out to and connect with other traditions of intellectual inquiry. In so doing they became something else. They ceased to be identifiably West Indian. They acquired a larger, more universal dynamic. It is in this movement, especially, that we can locate significant links in the chain between older traditions of West Indian thought and contemporary theoretical concern with the complex imperatives embedded in the processes of becoming postcolonial.

To see these connections is to remind ourselves that the crossing of seas has not been an experience enclosed by its past, of finite duration: it truly remains unfinished, an experience whose outcomes still retain the power to reverberate in the present.

This touches on my final point, which turns on the nature of the historical imagination. A dominating theme of Caribbean thought concerns the problem of the proximity of past and present. In the introduction I quoted James's remark that West Indians are 'more historical' than other peoples. There are many possible ways of interpreting a comment like this. But James, we know, had in mind the proximity of the past violence of slavery in the memories of the living. In different registers, consciousness of this unappeased past runs through every dimension of the Caribbean imagination. This may be experienced as a continuing burden, the present but a continuation of a longer duration of a state of unfreedom. Yet it can carry too a privileged sense of historical knowledge. After all, as Lamming observed, it was the migrants - not the hosts - who carried within them the knowledge that 'we have met before'.

Impressive in contemporary Caribbean cultures is the manner in which a vast range of narrative strategies has been employed in order to explore the interactions between past and present. All serve to shed light on how different moments of the historical past are organised or articulated in the present. This is apparent in popular forms, where long traditions of eschatological thought persist. It is apparent too in the more formally orchestrated narratives of imaginative writings, where highly varied resources are employed as inspiration: cosmological (in the work of Brathwaite), geological (in Wilson Harris), classical or mythological (in Derek Walcott), and so on. Whatever the distinctive personal idiom, and whatever the shared interactions between writers of different temperaments, a common theme is evident: the felt need to reimagine the very basis of historical inquiry, such that it can adequately represent the complexities of competing, simultaneous historical times.

Implicit in such endeavours lies a critique of the contemporary conventions of mainstream historiography. This is a literature which assumes that only by devising narratives which can fully encompass the 


\section{THE PREDICAMENT OF HISTORY}

past in the present can the burden of the past be appeased. Yet we - the British we - are coming to understand that this Caribbean past is also ours. The Middle Passage and the plantation are not only Caribbean matters. They impinge on our-British - present too. We have indeed met before. This is a past which breaks also into our present, and which needs to be identified, known and acknowledged. In ways we might not yet completely comprehend our - British - lives lie deep inside the Caribbean and colonial past.

Maybe in the future the most profound impact of Caribbean thought will be on our capacity to imagine the past, and to strive to bring it into consciousness.

\section{Notes}

1 Stephen Howe notes that the London Borough of Hackney has laid claim to James in the naming of one its libraries - as it has done for its municipal housing. One can't help but agree with him that, rather than being evidence of commemorative justice, this signals more the scale of lost hopes. In the same part of north London there exists the Claudia Jones Organization of Afro-Caribbean Women and (atop the longstanding New Beacon bookstore), the George Padmore Institute.

2 Mary Chamberlain, Narratives of Exile and Return (London: Macmillan, 1997), p. 86.

3 It would be important to track the degree to which the various traditions of West Indian thought we outline here were continued, appropriated or recast in the energetic retheorising of the relations between blackness and Britishness in the 1970s and 1980s. There is a huge literature here, as well as a veritable renaissance of black aesthetic practice. Race and Class and Race Today would signal appropriate starting points for such a genealogical investigation; and for the point when these issues began significantly to turn academic thinking, Centre for Contemporary Cultural Studies, The Empire Strikes Back: race and racism in seventies Britain (London: Hutchinson, 1982); and Paul Gilroy, 'There Ain't No Black in the Union Jack': the cultural politics of race and nation (London: Hutchinson, 1987).

4 West Indian Gazette, February 1962.

5 See especially Gilroy, 'There Ain't No Black'. 